\title{
USO DE ESPÉCIES DA CAATINGA NA ALIMENTAÇÃO DE REBANHOS NO MUNICÍPIO DE SÃO JOÃO DO CARIRI - PB'
}

\section{Use of species of Caatinga for feeding livestock in São João do Cariri - $P B$}

\author{
Kallianna Dantas Araujo ${ }^{2}$ \\ Renilson Targino Dantas ${ }^{3}$ \\ Albericio Pereira de Andrade ${ }^{4}$ \\ Henrique Nunes Parente ${ }^{5}$ \\ Érllens Éder-Silva ${ }^{6}$
}

\section{RESUMO}

Objetivou-se efetuar o levantamento das espécies vegetais da caatinga utilizadas na alimentação dos rebanhos, tipo de suporte alimentar oferecido aos animais na época seca, ocorrência de armazenamento da alimentação e redução dos rebanhos na época seca. Foram aplicados questionários a população rural de São João do Cariri - PB e confeccionado o mapa das propriedades rurais. Foi constatado que a maioria das propriedades apresenta baixos índices zootécnicos, com rebanhos pequenos, distribuídos entre bovinos, ovinos e caprinos, criados de forma extensiva na caatinga. As espécies Pilosocereus gounellei, Opuntia palmadora, Cereus jamacaru e Manihot glaziovi são as mais utilizadas para alimentação dos rebanhos, sendo oferecidas in natura e na forma conservada aos animais.

Palavras-chave: semiárido; sistema extensivo; herbivoria.

\begin{abstract}
Our purpose was to make a survey of the plant species of the caatinga used for feeding livestock, the type of food offered to support animals in the dry season, the occurrence of food storage and reduction of livestock in the dry season. Questionnaires were applied to the rural population of São João do Cariri - PB and a map of the farms was made. It was evident that most properties have low breeding indexes, with small flocks of cattle, sheep and goats reared extensively in the caatinga. The species Pilosocereus gounellei, Opuntia palmadora, Cereus jamacaru and Manihot glaziovi are most commonly used for feeding cattle, and they are given in natura and in the conserved form for the animals.
\end{abstract}

Keywords: semiarid; extensive system; herbivory.

1 Extraído do trabalho de tese do primeiro autor, financiado pela CAPES.

2 Geógrafa, Bolsista do INSA/MCT/Campina Grande - PB. Rua Silva Barbosa, 1.059, apto. 223, Edifício Boa Vontade, Bodocongó, Campina Grande - PB, CEP: 58.109-010. Fone: (083) 9992-3357. E-mail: kdaraujo@yahoo.com.br.

3 Meteorologista, Professor Associado do UACA/CTRN/UFCG. E-mail: renilson@dca.ufcq.edu.br.

4 Eng. Agrônomo, Pesquisador do INSA/MCT. E-mail: albericio@uol.com.br.

6 Eng. Agrônomo, Professor do IFCE, Campus Crato. E-mail: erllens_eder@hotmail.com. 


\section{INTRODUÇÃO}

A caatinga, vegetação caducifólia espinhosa, é predominante na região semiárida do Nordeste. De acordo com Gonzaga Neto et al. (2001) a caatinga constitui-se na mais importante fonte de alimentação para os rebanhos desta região, chegando a participar em até $90 \%$ da dieta de caprinos e ovinos.

Silva et al. (2004) menciona que a caatinga possui uma diversidade de espécies nativas com potencial forrageiro, sendo boa parte caducifólias e anuais, podendo ser consumidas pelos animais. Porém, devido à má distribuição das chuvas, geralmente concentradas em 3 a 4 meses do ano, os rebanhos tornam-se vulneráveis à estacionalidade da produção de forragem, deixando os produtores locais sem muitas alternativas alimentares, tornando a produção de alimentos um dos maiores desafios durante os meses de estiagem (GONZAGA NETO et al., 2001).

$\mathrm{Na}$ estação seca, os criadores buscam alternativas para suprir a carência alimentar dos seus rebanhos. Em contrapartida, durante o período chuvoso, grande quantidade de forragem nativa é desperdiçada, em função da grande disponibilidade de massa de forragem, bem como pelo pouco conhecimento quanto aos métodos de conservação de forragem pelos produtores (SILVA et al., 2004).

No entanto, pode-se preservar o excedente disponível nos períodos das chuvas, sob forma de feno, para ser utilizado no período de maior escassez alimentar, devendo-se selecionar as espécies que melhor se prestam para o processo e que apresentam as características forrageiras desejáveis (ARAÚJO et al., 1996).

Há uma preocupação entre os pecuaristas mais esclarecidos no armazenamento do excedente de forragens produzidas durante o período chuvoso, nas formas de feno ou silagem. No semiárido, esta prática ainda é pouco difundida, principalmente utilizando espécies forrageiras nativas, as quais apresentam boa palatabilidade, digestibilidade e considerável valor nutricional, mantendo suas qualidades quando conservadas adequadamente seja na forma de feno ou silagem. Dentre as espécies pode-se citar: mata-pasto (Senna obtusifolia L), malva-branca (Cassia uniflora), favela (Cnidoscolus phyllacanthus), jurema-preta (Mimosa tenuiflora), flor-de-seda (Calotropis procera), mandacaru (Cereus jamacaru), maniçoba (Manihot pseudoglaziovii), xiquexique (Pilosocereus gounellei), dentre outras (SILVA et al., 2004).
Drumond et al. (2000) corroboram com esta assertiva e mencionam que o aproveitamento de forrageiras nativas da caatinga como a maniçoba (Manihot pseudoglaziovii) é uma alternativa viável em virtude de seu potencial de produção, rusticidade e longevidade, devendo ser utilizadas como suplementação estratégica nos períodos de menor disponibilidade de forragens durante o ano, com o objetivo de aumentar a eficiência produtiva dos rebanhos caprinos, ovinos e bovinos do semiárido nordestino. Além de se tratar de uma alternativa alimentar nativa da própria caatinga, de baixo custo e de fácil adoção por parte dos produtores.

A caatinga vem sendo utilizada de forma empírica pelos criadores, sem o devido conhecimento do seu potencial produtivo, uso inadequado do solo e com pouca ou nenhuma preocupação ambiental (SILVA et al., 2004). A exploração da pecuária de forma extensiva como é feita atualmente na região deve ser reavaliada. Reduzir a pressão de pastejo e a manipulação da vegetação a um nível de tolerância compatível com as condições limitantes desse ecossistema seria prudente, pois a viabilidade da exploração pecuária da caatinga depende da sua capacidade de suporte (ANDRADE et al., 2006).

Com os objetivos de: identificar as espécies vegetais da caatinga utilizadas na alimentação dos rebanhos, e qual é o suporte alimentar oferecido aos animais na época seca; verificar a ocorrência de armazenamento de forragem na forma conservada; e a redução dos rebanhos na época seca e a caracterização dos sistemas de produção animal no município de São João do Cariri - PB; realizou-se esta pesquisa.

\section{MATERIAL E MÉTODOS}

\section{CARACTERIZAÇÃO DA ÁREA DE ESTUDO}

Aárea de estudo compreende o território municipal de São João do Cariri - PB, coordenadas geográficas $07^{\circ} 23^{\prime} 27^{\prime \prime}$ S e $36^{\circ} 31^{\prime} 58^{\prime \prime}$ W, com uma altitude média de $458 \mathrm{~m}$. Está localizado na zona fisiográfica do Planalto da Borborema, fazendo parte da mesorregião da Borborema e microrregião do Cariri Oriental (Figura 1). 


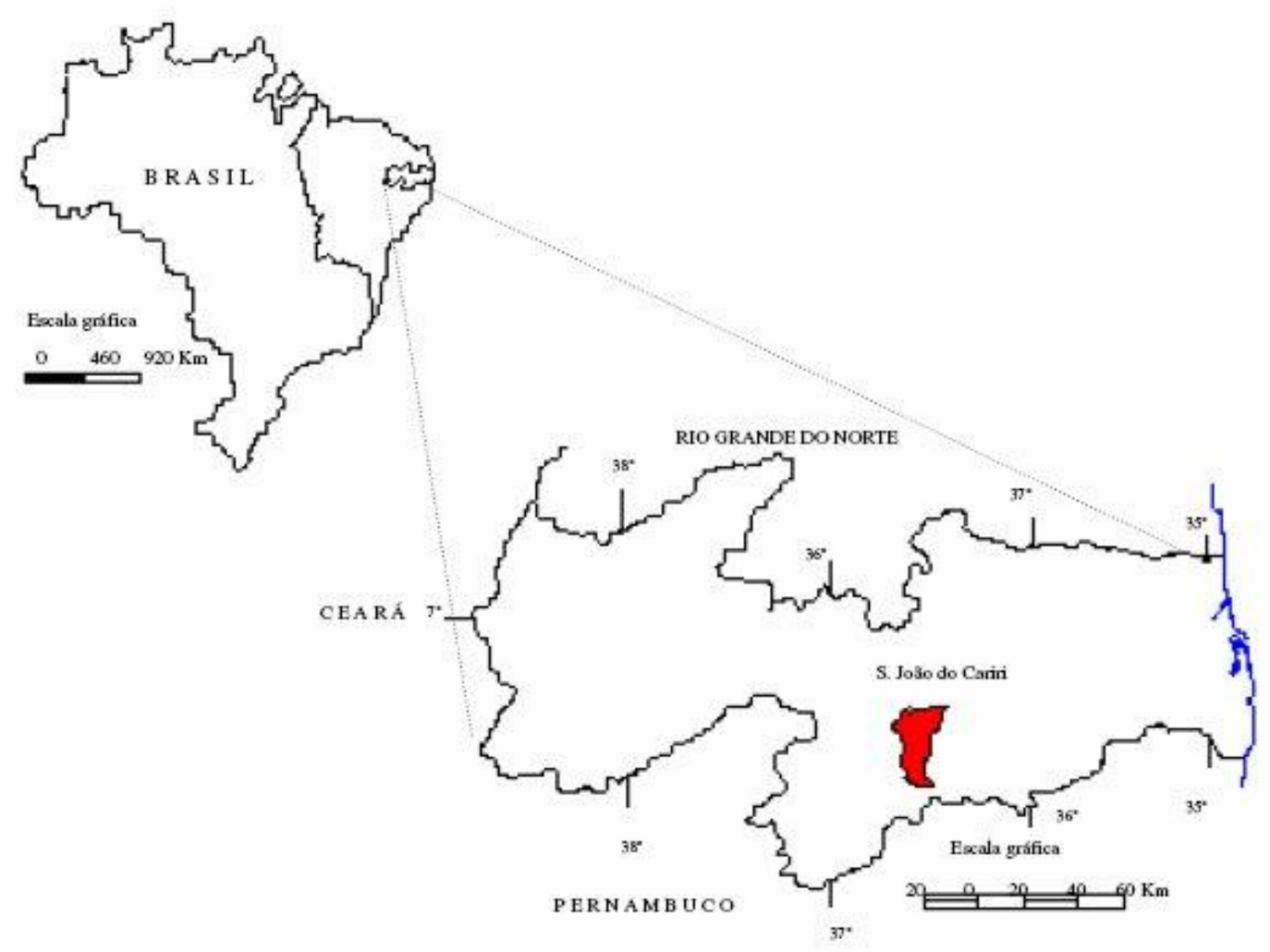

FIGURA 1 - LOCALIZAÇÃO DE SÃO JOÃO DO CARIRI - PB

A geologia da área em que está situado o município está constituída pelo embasamento cristalino de idade Pré-Cambriana, onde predominam gnaisses, migmatitos e granitos. O clima da região é do tipo Bsh - semiárido quente, com chuvas de verão-outono. De acordo com a classificação bioclimática de Gaussen, o clima é $2 b$ subdesértico quente com tendência tropical, com índice xerotérmico de 200 a 300. A temperatura média mensal oscila entre 27,2 e $23,1^{\circ} \mathrm{C}$, com precipitação média de $400 \mathrm{~mm} / \mathrm{ano}$ e umidade relativa do ar de $70 \%$ (GOVERNO DO ESTADO DA PARAÍBA, 1985).

De acordo com Chaves et al. (2002) os solos predominantes da área onde se localiza o município de São João do Cariri são: LUVISSOLO Crômico vértico, VERTISSOLO Cromado órtico e NEOSSOLO Lítico. Ocupando áreas menores e locais específicos da paisagem ainda ocorrem os CAMBISSOLO Háplico, NEOSSOLO Flúvico, PLANOSSOLO Háplico e afloramentos de rocha associado à NEOSSOLO Lítico.

O tipo de vegetação encontrada é a Caatinga (vegetação caducifólia espinhosa), adaptada à distribuição da precipitação e edáficas, formada em sua maioria por xerófitas caducifólias, constituída por uma mistura de estratos herbáceo, arbustivo e arbóreo de pequeno porte, de folhas caducas e pequenas, tortuosas, espinhentas e de elevada resistência às estiagens (SOUTO et al., 2007).

\section{APLICAÇÃO DOS QUESTIONÁRIOS AOS PROPRIETÁRIOS RURAIS DE SÃO JOÃO DO CARIRI - PB}

Foram aplicados 355 questionários aos proprietários de 60 propriedades rurais de São João do Cariri - PB, cuja área de cobertura foi à mesma realizada pelos nove Agentes Comunitários de Saúde do município (Tabela 1 e Figura 2), com o intuito de obter informações sobre o tamanho das propriedades e dos rebanhos, as espécies vegetais da caatinga de maior utilização na alimentação animal, parte das plantas da caatinga consumidas pelos animais, suporte alimentar oferecido aos animais na época seca, bem como armazenamento da alimentação animal e redução dos rebanhos na época seca. 
O número de questionários aplicados foi baseado na metodologia de amostragem de Rocha (1997) pela equação:

$$
n=\frac{0,96^{*} N}{\left\{0,01^{*}(N-1)+0,96\right\}}
$$

em que:

$\mathrm{n}$ = Número de questionários aplicados; rada.
A aplicação dos questionários foi feita seguindo a nomenclatura da Secretaria de Saúde do município, conforme apresenta o Programa de Agentes Comunitários de Saúde, sendo adotada a área de cobertura de cada um dos nove Agentes Comunitários de Saúde do município. Foram plotadas as coordenadas geográficas (latitude e longitude) de cada propriedade rural onde foi aplicado o questionário, para a confecção do mapa cartográfico. O mapa apresenta as coordenadas no sistema de projeção UTM.

TABELA 1- NÚMERO DE QUESTIONÁRIOS APLICADOS À POPULAÇÃO RURAL DE SÃO JOÃO DO CARIRI - PB

\begin{tabular}{|c|c|c|c|}
\hline $\begin{array}{c}\text { Agentes } \\
\text { Comunitários de Saúde }\end{array}$ & $\begin{array}{l}\mathrm{N}^{\circ} \text { de residências } \\
\text { por região }\end{array}$ & $\begin{array}{l}(\mathrm{n}) \\
\text { Questionários } \\
\text { aplicados }\end{array}$ & Propriedades Rurais \\
\hline I & 81 & 44 & Curral do Meio, Poço das Pedras, Cambira e Sacramento \\
\hline II & 90 & 47 & $\begin{array}{l}\text { Marinheiro, Mares, Gravatá, Currais Velhos, Forquilha } \\
\text { de Baixo, Forquilha de Cima, Macambira e Mulungu }\end{array}$ \\
\hline III & 90 & 47 & Lucas, Tanques, Riacho Fundo e Poço das Pedras \\
\hline IV & 53 & 34 & Uruçu de Cima, Uruçu de Baixo, Picoito e Veloso \\
\hline V & 150 & 59 & $\begin{array}{l}\text { Pombo, Caixa D'Água, Logradouro, } \\
\text { Boi Preto e Malhada da Roça }\end{array}$ \\
\hline $\mathrm{VI}$ & 33 & 25 & $\begin{array}{c}\text { Cachoeira, Figueiras, Barra de Figueiras, Serraria, } \\
\text { Riacho dos Cachorros, Saco, Barragem, Fazenda Boa } \\
\text { Vista, Ponta da Serra, Bom Jardim, Bonanza, Boa } \\
\text { Vista, Alagamar, Olho D'Água e Craibeira }\end{array}$ \\
\hline VII & 58 & 36 & $\begin{array}{l}\text { Jurema, Olho D’Água de Baixo, Floresta, Tanques, } \\
\text { Albuquerque, Cachoeira, Siriema, Riacho do Piancó, } \\
\text { Contendas, Malhada da Ema, Barbosa e Mudubin }\end{array}$ \\
\hline VIII & 44 & 30 & $\begin{array}{c}\text { Santana, Maracajá, Arara, Dois Riachos, Ria- } \\
\text { cho Salgado, Mineiro e Santa Clara }\end{array}$ \\
\hline IX & 50 & 33 & Uruçu de Baixo, Várzea Grande, Alagamar e Farias \\
\hline
\end{tabular}




\section{Localização dos sítios pesquisados}

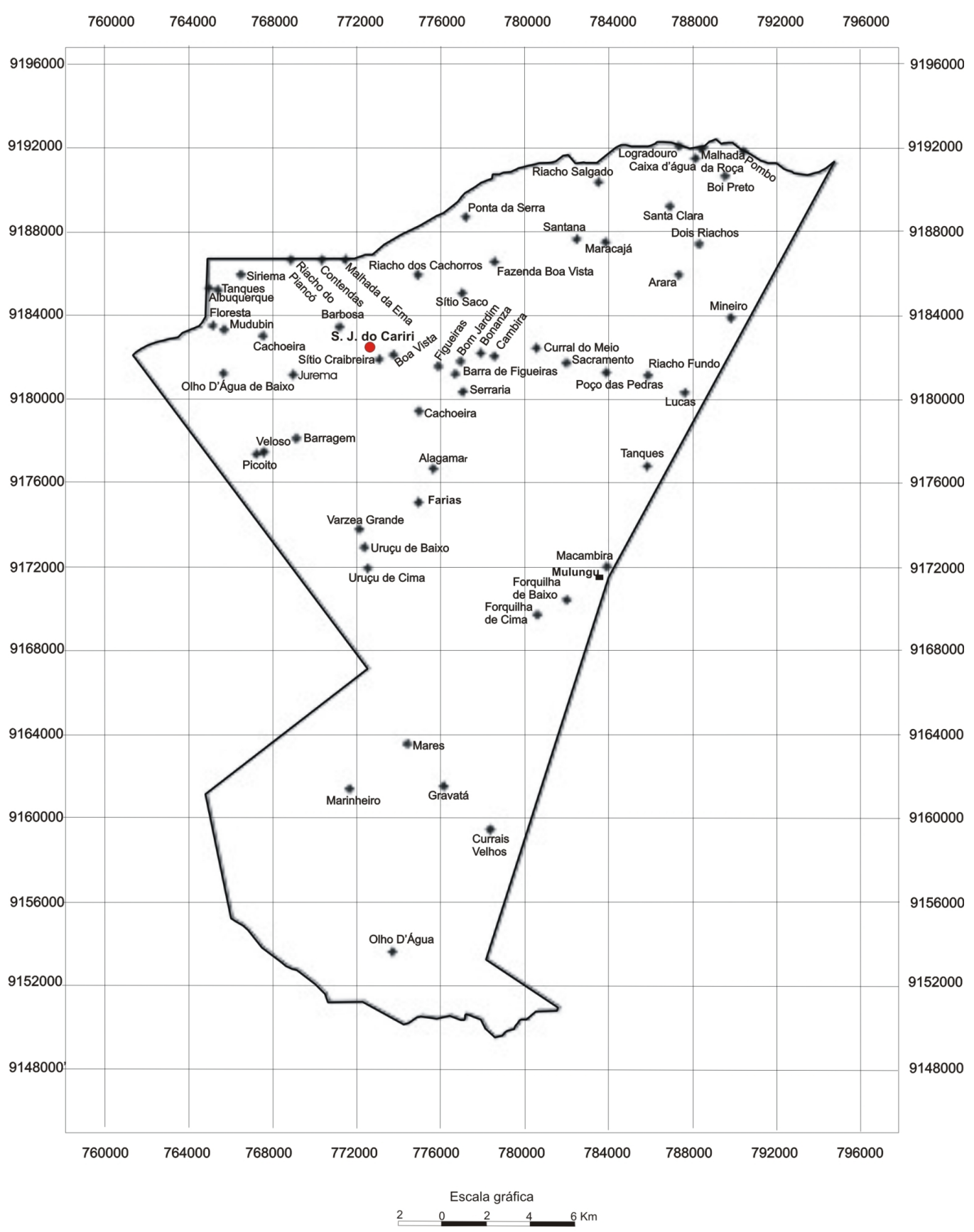

Fonte: Mapa Municipal Estatístico do IBGE, 2000, Datum SAD 69.

Dados da pesquisa de campo com base na nomenclatura dos Agentes Comunitários de Saúde, do município de São João do Cariri, PB.

FIGURA 2 - MAPA DE LOCALIZAÇÃO DOS SÍTIOS ONDE FORAM APLICADOS OS QUESTIONÁRIOS DE COLETA DE DADOS, COM BASE NA ÁREA DE COBERTURA DOS AGENTES COMUNITÁRIOS DE SAÚDE, DE SÃO JOÃO DO CARIRI - PB 
ARAUJO, K. D. et al. Uso de espécies da Caatinga na alimentação...

\section{RESULTADOS E DISCUSSÃO}

\section{PERFIL DAS PROPRIEDADES E REBANHOS}

Observou-se que a maioria dos proprietários rurais do universo pesquisado no município de São João do Cariri tem uma produção pecuária reduzida (Tabela 2 ), com rebanhos pequenos $(39,22 \%)$, que variam de 1 a 220 animais, com média de aproximadamente 23 animais, distribuídos entre bovinos $(23,91 \%)$, ovinos $(7,49 \%)$ e caprinos $(5,46 \%)$, os quais são criados de forma extensiva na caatinga na maioria das propriedades rurais (Tabela 3 ).

TABELA 2 - TAMANHO DOS REBANHOS PERTENCENTES AOS PROPRIETÁRIOS RURAIS DE SÃO JOÃO DO CARIRI - PB

Tamanho dos rebanhos

Pequeno (até 25 cabeças)

Médio $(26$ - 50)

Grande ( $>50$ cabeças)
Universo amostral (\%)

39,22

9,24

8,12

TABELA 3 - TIPOS DE REBANHOS PERTENCENTES AOS PROPRIETÁRIOS RURAIS DE SÃO JOÃO DO CARIRI - PB

Tipos de rebanhos

Caprino+Ovino+Bovino

Bovino

Ovino + Bovino

Caprino + Ovino

Ovino

Caprino

Caprino + Bovino

Não responderam

Rebanho não especificado

Não possuem animais
Universo amostral (\%)

27,03

23,91

14,98

7,86

7,49

5,46

4,51

3,67

3,30

1,79 
As propriedades apresentam dimensões que variam entre 01 a 1.030 ha, cuja média é de 46,9 ha. A densidade varia de praticamente 0 a 22 animais por hectare, resultando em um valor médio de 1 a 2 caprinos por hectare, superior à densidade encontrada por Leal et al. (2003) que variou entre 0,77 e 0,55 caprinos por hectare na região semiárida de Xingó, localizada entre os estados de Alagoas, Bahia e Sergipe.

De acordo com Quadros (2004) em geral, a utilização de pastagens naturais, principalmente a caatinga, para criação de caprinos e ovinos, apresenta baixa capacidade de suporte ( 1 ovelha/ha), em contraste às artificiais, formadas de gramíneas, cujo potencial de produção pode suportar mais de 25 ovelhas/ha. Araújo Filho et al. (2002) citam que em pastejo contínuo em caatinga raleada, a taxa de lotação para ovinos da raça Morada Nova de 0,6 cab/ha/ano, deve ser a recomendada para a caatinga raleada no sertão cearense. Sendo que a taxa de lotação pode ser afetada pela estação do ano, pelo ano e pela época de parição.

Leal et al. (2003) consideram as altas taxas de lotação de caprinos como um fator de empobrecimento e redução no porte da vegetação da caatinga em níveis que podem levar a degradação quando associados a outras formas de pressão antrópica. Nesse sentido, a compreensão da interferência do animal no ecossistema da caatinga precisa ser mais bem compreendida, uma vez que a pecuária é considerada uma das principais causas da degradação da caatinga e não são poucos os estudos que buscam uma melhor utilização do suporte forrageiro oferecido por esse ecossistema. Daí ser primordial que a exploração desse suporte forrageiro seja de forma compatível com o potencial de recuperação da vegetação (ANDRADE et al., 2006).

\section{ESPÉCIES VEGETAIS DA CAATINGA DE MAIOR UTILIZAÇÃO ANIMAL}

De acordo com as informações dos proprietários rurais a frequência das quatro espécies vegetais da caatinga de maior utilização para uso animal é o xiquexique - Pilosocereus gounellei $(17,88 \%)$, seguido da palmatória - Opuntia palmadora (15,61\%), mandacaru Cereus jamacaru $(9,70 \%)$ e maniçoba - Manihot glaziovii $(6,26 \%)$ (Figura 3).

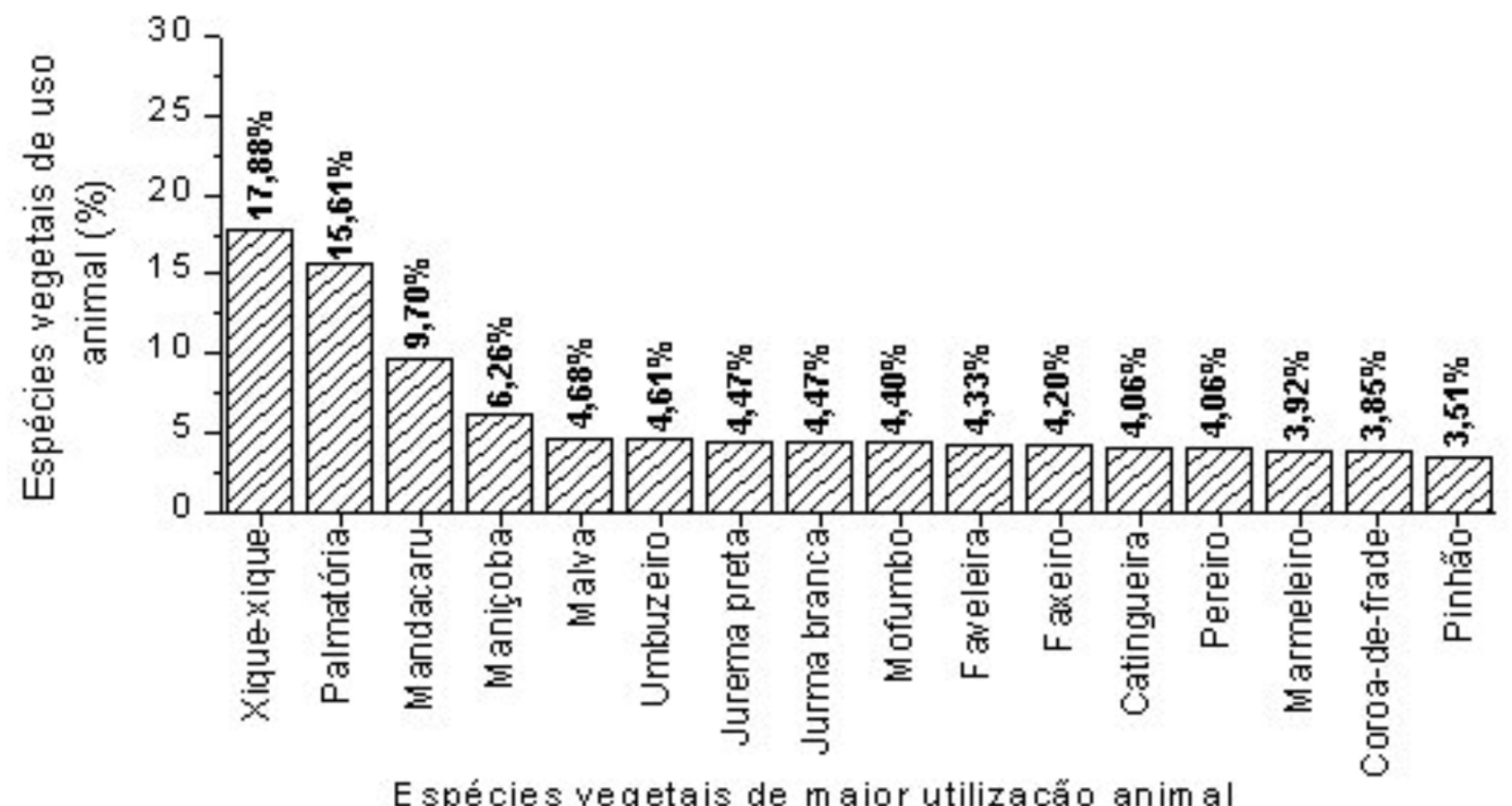

E spécies vegetais de $m$ aior utilizaçẫo anim al

FIGURA 3 - ESPÉCIES VEGETAIS DE MAIOR UTILIZAÇÃO ANIMAL PELOS PROPRIETÁRIOS RURAIS DE SÃO JOÃO DO CARIRI - PB 
Em estudo realizado por Leal et al. (2003) na região semiárida de Xingó, localizada entre os estados de Alagoas, Bahia e Sergipe, constataram que das 53 espécies de plantas listadas e apresentadas aos proprietários de caprinos, as espécies juazeiro - Zizyphus joazeiro, palmatória - Opuntia palmadora e quixabeira - Sideroxylon obtusifolium apresentaram o maior número de registros, sendo indicadas pelos 32 entrevistados.

Observou-se in loco que os caprinos consomem xique-xique - Pilosocereus gounellei, catingueira - Caesalpinia pyramidalis, marmeleiro - Croton sonderianus, coroa de frade - Melocactus sp., panasco - Aristida adscensionis, além de cascas de troncos de árvores (Figura 4A a 4D) principalmente de catingueira - Caesalpinia pyramidalis e marmeleiro - Croton sonderianus. Dados semelhantes foram encontrados por Lima Júnior (2006) ao verificar que a frequência das forrageiras mais consumidas pelos caprinos moxotó na vegetação da caatinga, foram panasco - Aristida adscensionis (37,04\%), malva - Malva sp. $(27,16 \%)$, catingueira - Caesalpinia pyramidalis (12,35\%), marmeleiro - Croton sonderianus $(6,17 \%)$, pereiro - Aspidosperma pyrifolium $(2,47 \%)$ e tronco $(1,23 \%)$, em estudo realizado no município de São João do Cariri - PB.

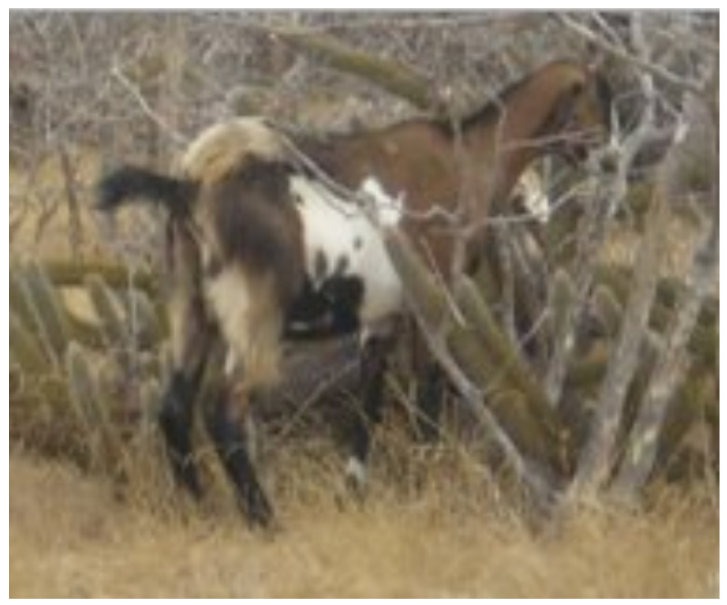

A

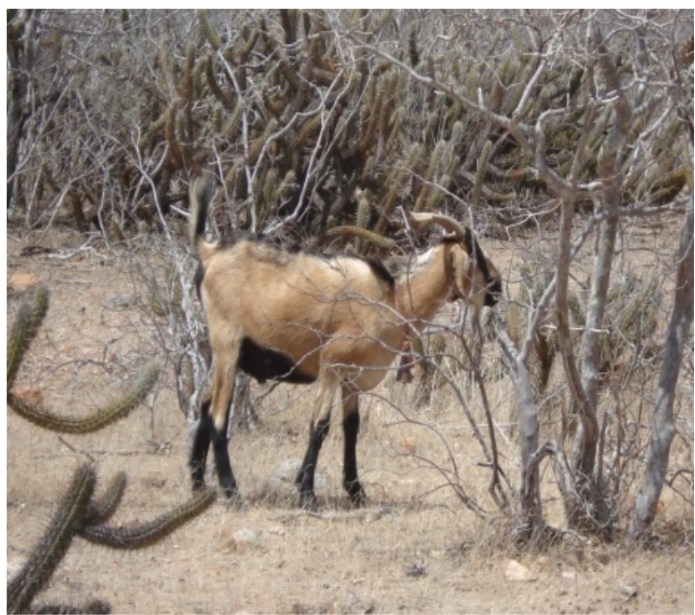

C

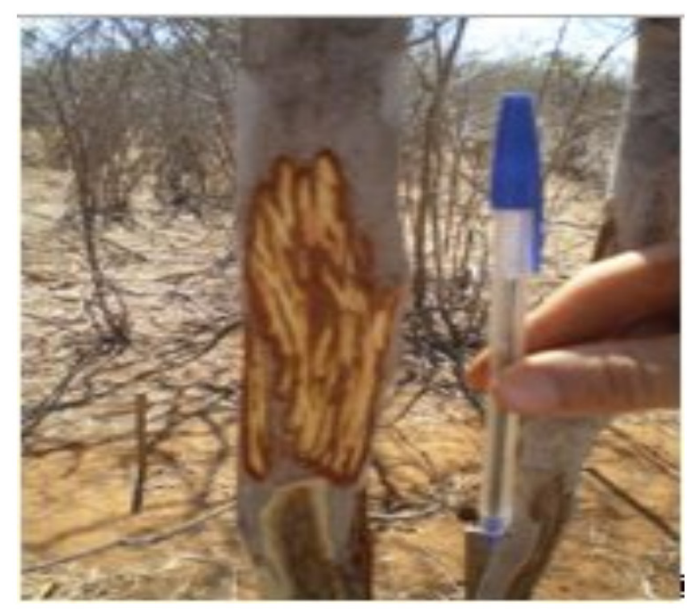

B

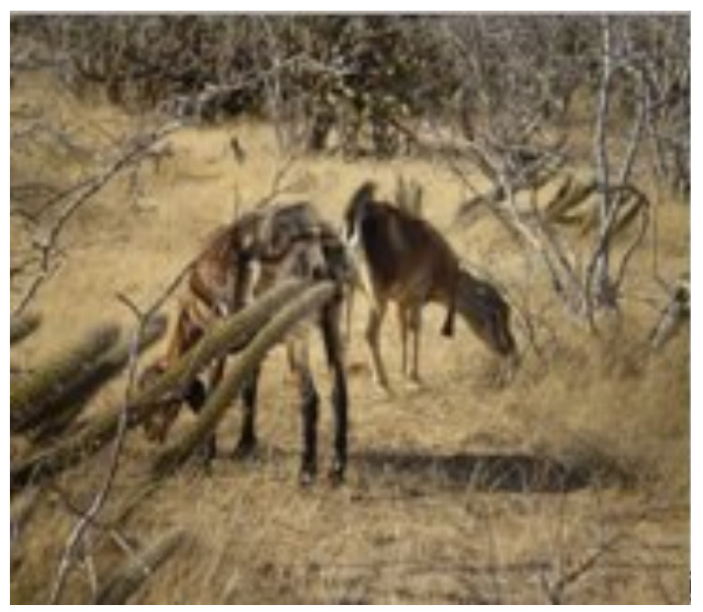

D

FIGURA 4 - CAPRINOS SE ALIMENTANDO DE TRONCOS DE CATINGUEIRA - Caesalpinia pyramidalis (A) E (B), XIQUE-XIQUE - Pilosocereus gounellei (C), PANASCO - Aristida spp. (D), EM SÃO JOÃO DO CARIRI - PB 
De acordo com Leal et al. (2003) os resultados destes estudos indicam que os caprinos são importantes herbívoros para a vegetação de caatinga, pois utilizam partes da maioria das espécies de árvores e arbustos encontrados na região como forragem. Os dados sugerem que estes animais são bastante generalistas, uma vez que comem plântulas e todas as partes de plantas adultas, da maioria das espécies presentes na área.

Assim, a herbivoria por caprinos constitui um importante fator de seleção natural capaz de afetar a abundância e a distribuição geográfica de espécies lenhosas na caatinga, especificamente arbustos e árvores perenifólias como o juazeiro (Zizyphus joazeiro) e umbuzeiro (Spondias tuberosa) e, sobretudo as espécies decíduas que compõem o grupo com maior probabilidade de sofrer reduções populacionais, como aroeira (Myacrodruon urundeuva) e amburana (Commiphora leptophloeos) com ciclo reprodutivo parcial ou completo na época seca, pois estão acessíveis ao pastejo na época em que os caprinos dependem exclusivamente da vegetação lenhosa como fonte de alimento.

Além disso, em condições de superpastejo, ovinos e caprinos podem induzir mudanças substanciais na florística da caatinga, quer pelo anelamento dos troncos das árvores e arbustos, causando-lhes a morte, ou pelo consumo das plântulas, impedindo a renovação do estoque de espécies lenhosas (ARAÚJO FILHO; CRISPIM, 2002).

\section{PARTE DAS PLANTAS DA CAATINGA CONSUMIDAS PELOS ANIMAIS}

Verificou-se que $31,37 \%$ dos produtores rurais afirmaram que os animais consomem todas as partes das plantas desde plântula, folha nova, folha madura, caule e folhas, flor, ramos e frutos (Figura 5).

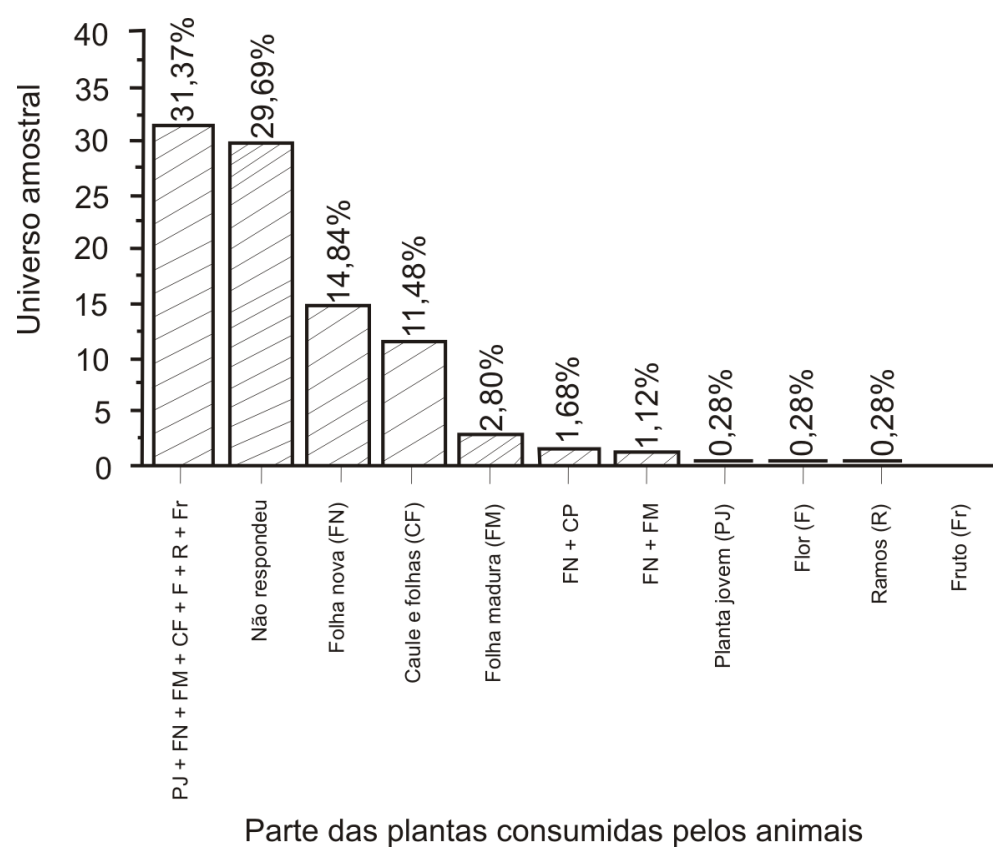

FIGURA 5 - PARTE DAS PLANTAS CONSUMIDAS PELOS ANIMAIS, SEGUNDO RELATO DOS PROPRIETÁRIOS RURAIS DE SÃO JOÃO DO CARIRI - PB

Leal et al. (2003) corroboram com esta assertiva ao afirmarem que os caprinos parecem hábeis também em consumir uma variedade enorme de tipos de frutos, sejam eles secos ou carnosos, assim como flores e sementes de tipos e tamanhos variados. $\mathrm{Na}$ estação chuvosa, os caprinos preferem as plantas herbáceas com flor e brotos da vegetação lenhosa. Na estação seca, quando o estrato herbáceo desaparece, os animais se alimentam de folhas, flores, frutos, sementes, brotos e cascas de árvores e arbustos, obtidas no chão ou até dois metros de altura na vegetação, uma vez que a remoção concentra-se nos primeiros dois metros da vegetação (ARAÚJO FILHO, 1989). 


\section{SUPORTE ALIMENTAR NA ÉPOCA SECA CURTA OU PROLONGADA}

Com relação ao suporte alimentar no período seco, constatou-se que $33,90 \%$ oferecem aos seus animais ração concentrada; resíduo, torta, milho, algaroba, trigo, cama de galinha ou palma forrageira. Pequena parte dos produtores $(3,64 \%)$ proporciona outro tipo de suporte alimentar utilizando capim verde (volumoso).

Poucos produtores utilizam silagem $(1,40 \%)$ sendo esta de milho ou sorgo e feno $(1,12 \%)$. Verificou-se ainda que uma parte expressiva dos produtores $(19,33 \%)$ emprega a associação concentrando outro tipo de suporte alimentar (Figuras 6 e 7).

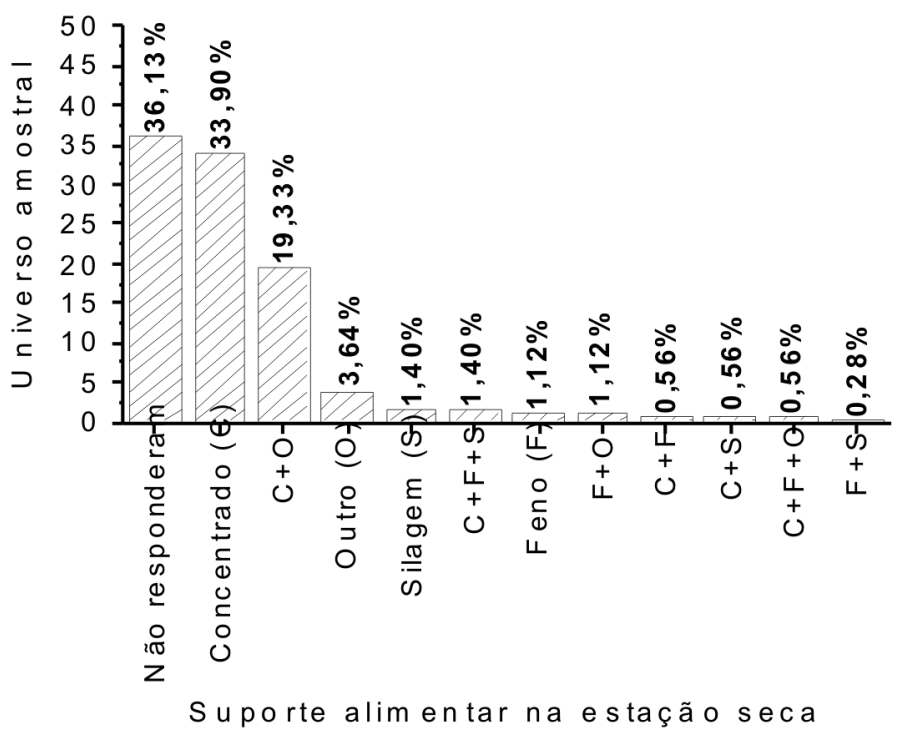

FIGURA 6 - SUPORTE ALIMENTAR NA ESTAÇÃO SECA, EM SÃO JOÃO DO CARIRI - PB

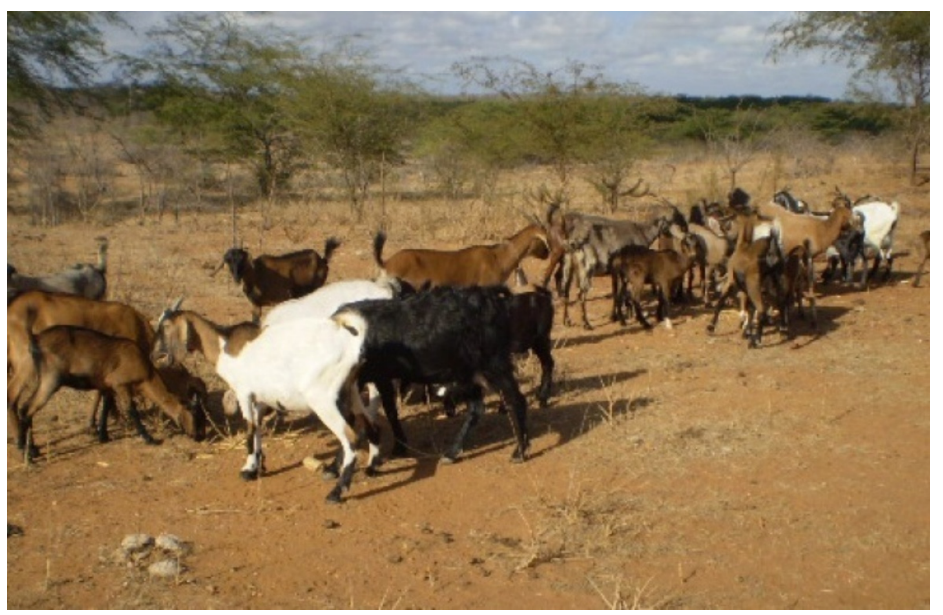

FIGURA 7 - USO DE ALGAROBA (Prosopis juliflora) COMO SUPLEMENTO PARA OS CAPRINOS NO SÍTIO FLORESTA, EM SÃO JOÃO DO CARIRI - PB 
Vale ressaltar que embora a algaroba (Prosopis juliflora) seja uma espécie economicamente promissora, uma vez que apresenta qualidades como forrageira e produz lenha e carvão de boa qualidade, esta espécie tem se revelado uma invasora agressiva pela sua adaptação às condições edafoclimáticas de parte do semiárido nordestino, decorrente da falta de manejo dos plantios, somada ao caráter extensivo da pecuária regional, transformando o que seria uma solução em um problema, já que a invasão da algaroba (Prosopis juliflora) reduz a diversidade e a riqueza taxonômica de espécies da caatinga (OLIVEIRA, 2006).

De acordo com Andrade et al. (2006) a produção de alimento para os animais, ainda se constitui no maior problema para o desenvolvimento da pecuária no semiárido. Sem dúvidas o cultivo de plantas forrageiras da caatinga como lavoura xerófila regular, em áreas de déficit hídrico, pode ser a opção mais vantajosa para a agricultura do semiárido. Da mesma forma, a prática de fazer feno deve ser encarada como um complemento desse sistema de produção agrícola. Entretanto, ainda, são necessários estudos sobre feno de forrageiras de espécies da caatinga, pois grande parte dos conhecimentos até então adquiridos são oriundos de outras regiões.

Ainda segundo os autores, durante o período chuvoso, as forrageiras anuais têm rápido crescimento e curta duração do ciclo fenológico, resultando em forte periodicidade na disponibilidade da oferta de forragem desse tipo de vegetação. Assim, a produção de fitomassa do estrato herbáceo excede a capacidade de consumo dos rebanhos, o que permite conservar o excedente disponível, sob forma de fenos ou silagem, para serem utilizados no período de maior escassez de alimentos, selecionando as espécies que melhor se prestam para conservação e que apresentem características forrageiras desejáveis. Porém, são necessários estudos sobre o manejo e utilização dessas forrageiras, de forma que garanta sua presença anual no ecossistema.

\section{ARMAZENAMENTO DA ALIMENTAÇÃO ANIMAL E REDUÇÃO DOS REBANHOS NA ÉPOCA SECA}

A maioria dos produtores rurais não armazena alimentos para os animais $(68,91 \%)$. Dos criadores que estocam alimento $30,53 \%$ armazenam por menos de um ano e somente $0,56 \%$ dos produtores armazenam o estoque para mais de um ano (Figura 8 A). Esses dados corroboram com as informações levantadas por Sousa (2007) nos municípios de Boa Vista, Cabaceiras e São João do Cariri - PB. Nesse sentido, a redução dos rebanhos pelos produtores, é feita antes da estação seca $27,17 \%$ e $19,05 \%$ fazem a redução durante as estiagens (Figura 8B). O que implica dizer que em algumas propriedades a pecuária é afetada nos períodos de longa seca.

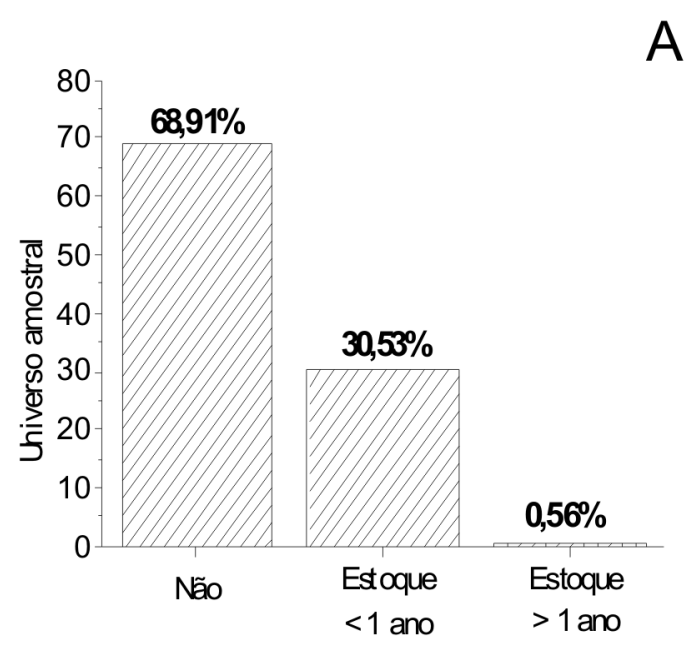

Amazenamento da alimentação animal

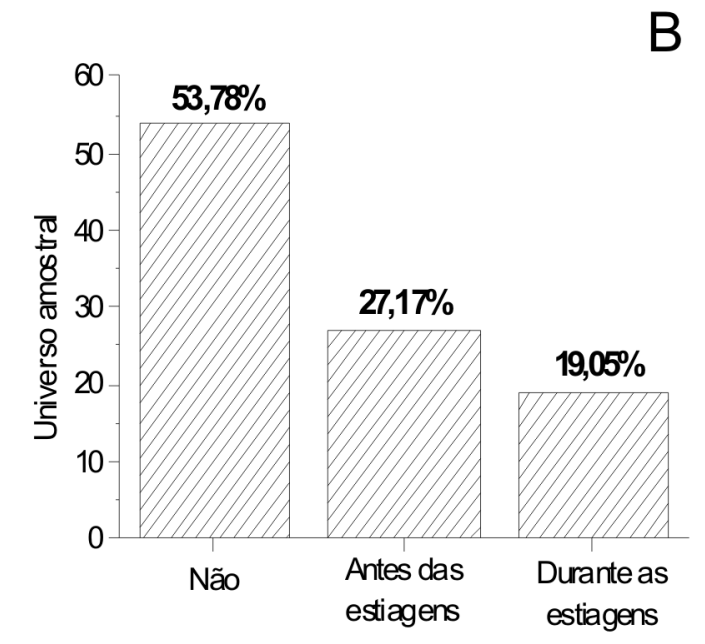

Redução dos rebanhos 
Alencar (2008) observou, em estudo realizado nos municípios da Bacia do rio Sucuru (Amparo, Ouro Velho, Prata, Sumé, Coxixola e Serra Branca), que quando a pecuária é comprometida, com redução do rebanho, ou em muitos casos, deixa de ser explorada, os produtores buscam na exploração da caatinga e das espécies nativas, alternativas de sobrevivência, como o uso da lenha para a fabricação de carvão.

Desse modo, são necessários mais estudos para ampliar as hipóteses testadas nesse trabalho e alertar os tomadores de decisão sobre a exploração dos recursos naturais da caatinga. Não esquecendo que explorar as potencialidades do semiárido de forma sustentável e economicamente viável exige a compreensão de que a natureza tem que ser respeitada e ela é quem deve determinar a forma e a época em que as atividades agrícolas podem ser executadas. Na verdade, pouco se tem por fazer para poder explorar as potencialidades do semiárido, o que é necessário é aprender com a diversidade da natureza dessa região e pensar conceitualmente a semiaridez como vantagem e não como desvantagem (ANDRADE et al., 2006).

\section{CONCLUSÕES}

- A produção pecuária em São João do Cariri - PB é composta por rebanhos pequenos, distribuídos entre bovinos, ovinos e caprinos, criados extensivamente na caatinga;

- $\quad$ As espécies xique-xique (Pilosocereus gounellei), palmatória (Opuntia palmadora), mandacaru (Cereus jamacaru) e maniçoba (Manihot glaziovi) são as mais utilizadas para alimentação dos rebanhos, sendo oferecidas in natura e na forma conservada aos animais;

- A participação da comunidade nesta pesquisa favoreceu o conhecimento sobre os sistemas de produção utilizados pelos proprietários rurais de São João do Cariri - PB, fazendose necessárias orientações que melhorem a forma de utilização das espécies existentes na caatinga e de técnicas de processamento e armazenamento para alimentação animal como a produção de feno e silagem.

\section{REFERÊNCIAS}

ALENCAR, M. L. S. de. Os sistemas hídricos, o bioma caatinga e o social na bacia do rio sucuru: riscos e vulnerabilidades. 157 f. Tese (Doutorado em Engenharia Agrícola) - Centro de Tecnologia e Recursos Naturais, Universidade Federal de Campina Grande, Campina Grande, 2008.

ANDRADE, A. P. de; SOUZA, E. S. de; SILVA, D. S. da; SILVA, I. de F. da; LIMA, J. R. S. Produção animal no bioma caatinga: paradigmas dos "pulsos-reservas". In: SIMPÓSIOS DA 43 REUNIÃO ANUAL DA SBZ, 2006, João Pessoa. Anais... João Pessoa: Sociedade Brasileira de Zootecnia, 2006. CD-ROM.

ARAÚJO FILHO, J. A. de; SOUZA NETO, M. de; NEIVA, J. N. M.; CAVALCANTI, A. C. R. Desempenho produtivo de ovinos da raça morada nova em caatinga raleada sob três taxas de lotação. Ciência Agronômica, v. 33, n.1, p. 51-57, 2002.

ARAÚJO FILHO, J. A. Manipulação da vegetação lenhosa da caatinga para fins pastoris. In: EMBRAPA (Org.). Curso de melhoramento e manejo de pastagem nativa no trópico semiárido. Teresina: EMBRAPA-CPAMN/SPI, 1989, p. 41-58.

ARAÚJO FILHO, J. A. de; CRISPIM, S. M. A. Pastoreio combinado de bovinos, caprinos e ovinos em áreas de caatinga no nordeste do Brasil. In: CONFERÊNCIA VIRTUAL GLOBAL SOBRE PRODUÇÃO ORGÂNICA DE BOVINOS DE CORTE, set./out. 2002, Concórdia.

ARAÚJO, E. C. de; VIEIRA, M. E. de Q.; CANTARELLI, R. F. Valor Nutritivo e Consumo Voluntário de Forrageiras Nativas da Região Semi-Árida de Pernambuco. V - Marmeleiro (Croton sonderianus, Muell. Arg.). In: REUNIÃO DA SOCIEDADE BRASILEIRA DE ZOOTECNIA, 33., 1996, Fortaleza. Anais... Fortaleza: SBZ, 1996.

CHAVES, L. H. G.; CHAVES, I. B.; VASCONCELOS, A. C. F.; SILVA, A. P. P. Salinidade das águas superficiais e suas relações com a natureza dos solos na bacia escola do açude namorados e diagnóstico do uso e degradação das terras. Campina Grande: Convênio Banco do Nordeste do Brasil/ UFPB/FINEP, 2002. 114 f. Relatório técnico.

DRUMOND, M. A.; KIILL, L. H. P.; LIMA, P. C. F.; OLIVEIRA, M. C. de; OLIVEIRA, V. R. de; ALBUQUERQUE, S. G. de A.; NASCIMENTO, C. E. de S.; CAVALCANTI, J. Avaliação e identificação de ações prioritárias para a conservação, utilização sustentável, e repartição de benefícios da biodiversidade do bioma caatinga: estratégias para o uso sustentável da biodiversidade da caatinga. Documento para discussão no GT Estratégias para o Uso Sustentável. Petrolina, 2000, p. 23. 
GONZAGA NETO, S.; BATISTA, A. M. V.; CARVALHO, F. F. R. de; MARTÍNEZ, R. L. V.; BARBOSA, J. E. A. S.; SILVA, E. O. Composição bromatológica, consumo e digestibilidade In Vivo de dietas com diferentes níveis de feno de catingueira (Caesalpinea bracteosa), fornecidas para ovinos Morada Nova. Revista Brasileira de Zootecnia, v. 30, n. 2, p. 553-562, 2001.

GOVERNO DO ESTADO DA PARAÍBA. Secretaria da Educação. Universidade Federal da Paraíba. Atlas Geográfico da Paraíba. João Pessoa: Grafset, 1985. 100 p.

LEAL, I. R.; SILVA, A. V. da; TABARELLI, M. Herbivoria por caprinos na caatinga da região de Xingó: uma análise preliminar. In: LEAL, I. R.; TABARELLI, M.; SILVA, J. M. C. (Org.). Ecologia e conservação da Caatinga. Recife: Editora da Universidade Federal de Pernambuco, 2003. p. 695-715.

LIMA JÚNIOR, V. de. Caracterização da dieta e avaliação de métodos de estimativa de consumo em caprinos suplementados na caatinga. 81f. Dissertação (Mestrado em Zootecnia) - Centro de Ciências Agrárias, Universidade Federal da Paraíba, Areia, 2006.

OLIVEIRA, F. X. de. Impactos da invasão da Algaroba Prosopis juliflora (sw.) DC. - sobre o de componente arbustivoarbóreo da caatinga nas microrregiões do Curimataú e do Seridó nos estados da Paraíba e do Rio Grande do Norte. $138 \mathrm{f}$. Dissertação (Mestrado em Agronomia) - Centro de Ciências Agrárias, Universidade Federal da Paraíba, Areia, 2006.
QUADROS, D. G. de. Pastagens para ovinos e caprinos. In: SIMPOGECO - SIMPÓSIO DO GRUPO DE ESTUDOS DE CAPRINOS E OVINOS, 1., 2004, Salvador: Escola de Medicina Veterinária da Universidade Federal da Bahia, 2004. 34p.

ROCHA, J. S. M. da. Manual de projetos ambientais. Santa Maria: Imprensa Universitária, 1997. 423 p.

SILVA, D. F. da; SILVA, A. M. de A.; LIMA, A. B. de; MELO, J. R. M. de. Exploração da caatinga no manejo alimentar sustentável de pequenos ruminantes. In: CONGRESSO BRASILEIRO DE EXTENSÃO UNIVERSITÁRIA, 2., 2004, Belo Horizonte, Anais... Belo Horizonte, p.1-8, 2004.

SOUSA, R. F. de. Terras agrícolas e o processo de desertificação em municípios do semi-árido paraibano. 180f. Tese (Doutorado em Engenharia Agrícola) - Centro de Tecnologia e Recursos Naturais, Universidade Federal de Campina Grande, Campina Grande, 2007.

SOUTO, P. C.; SOUTO, J. S.; SANTOS, R. V. dos; SALES, F. das C.; LEITE, R. de A.; SOUSA, A. A. de. Decomposição da serapilheira e atividade microbiana em área de caatinga. In: CONGRESSO BRASILEIRO DE CIÊNCIA DO SOLO, 31., 2007, Gramado. Anais... Gramado, SBCS, 2007. CD-ROM. 
ARAUJO, K. D. et al. Uso de espécies da Caatinga na alimentação...

ANEXO 1. QUESTIONÁRIO DE COLETA DE DADOS

DATA:
NOME DAPROPRIEDADE:
NOMEDO(A)PRODUTOR(A):

\begin{tabular}{|c|c|c|}
\hline 1. SITUAÇÃO ESCOLAR & 2. RENDA FAMILIAR & \\
\hline $\begin{array}{l}\text { Alfabetizado ( ) sim ( ) não } \\
\text { a) } 1^{\circ} \mathrm{Grau} \text { incompleto ( ) c) } 2^{\circ} \text { Grau completo ( ) } \\
\text { b) } 1^{\circ} \mathrm{Grau} \text { completo ( ) d) } 3^{\circ} \text { Grau completo ( ) }\end{array}$ & $\begin{array}{l}\text { a) Menos de } 1 \text { salário mínimo ( ) } \\
\text { b) } 1 \text { salário mínimo ( ) } \\
\text { c) Até } 1 \frac{1}{2} \text { salário mínimo ( ) }\end{array}$ & $\begin{array}{l}\text { d) Até } 2 \text { salários mínimos ( ) } \\
\text { e) Até } 3 \text { salários mínimos ( ) } \\
\text { f) Acima de } 5 \text { salários mínimos ( ) }\end{array}$ \\
\hline
\end{tabular}

\section{FONTE DE RENDA}

a) Aposentadoria ( )

b) Trabalho assalariado ( )

c) Renda enviada por parente ( ) d) Autônomo ( )

e) Agricultura ( )

f) Pecuária ( ) g) Mineração ( )

h) Extrativismo ( )

i) Outro:
LOCALIDADE: TAMANHODA PROPRIEDADE: $N^{\circ}$ DE PESSOAS RESIDENTES:

\section{ABASTECIMENTO DE ÁGUA}

\subsection{Armazenamento de água das chuvas}

a) Caixa d'água ( )

b) Cisternas ( )

c) Açudes ( )

d) Outro:
5.2. Fonte principal de água

a) Poço amazonas ( )

b) Poço tubular ( )

c) Açude ( )

\section{RECURSOS EXISTENTES}

a) Energia elétrica ( )

b) Água encanada ( )

d) Fogão gás ( )

c) Rede de esgoto ( ) f) Antena parabólica ( )

\section{UTILIZAÇÃO DA CAATINGA}

\begin{tabular}{|c|c|c|c|}
\hline $\begin{array}{l}\text { a) Lenha (uso doméstico) ( ) } \\
\text { b) Lenha (carvão) ( ) } \\
\text { c) Lenha (olaria) ( ) }\end{array}$ & $\begin{array}{l}\text { d) Lenha (venda) ( ) } \\
\text { e) Cerca ( ) } \\
\text { f) Outro: }\end{array}$ & $\begin{array}{l}\text { g) Frutos( ) Quais: } \\
\text { h) Sementes ( ) Quais: } \\
\text { i) Plantas medicinais ( ) Quais: }\end{array}$ & j) Tipos de madeiras: \\
\hline
\end{tabular}

\section{TÉCNICAS DE USO DA CAATINGA}

7.1. Tipos de técnicas de uso da caatinga

Sim ( ) Não ( ) Ocasionalmente ( )

a) Raleamento ( ) b) Queima de espécies cactáceas ( )

c) Plantio de palma ( ) d) Plantio de outras espécies forrageiras ( )

\section{2. Área destinada à reserva ambiental}

$\operatorname{Sim}(\quad)$ Não ( )

Tamanho da área:

\section{PECUÁRIA}

\begin{tabular}{|l|l|}
\hline 8.1. Sistema de manejo de animais & 8.2. Tamanho dos rebanhos \\
\hline a) Controle zootécnico Sim ( ) Não ( ) & a) Pequeno - até 25 cabeças ( ) \\
b) Vermifugação $\operatorname{Sim}($ ) Não ( ) & b) Médio - de 26 a 50 cabeças ( ) \\
c) Vacinação & c) Grande - acima de 50 cabeças ( )
\end{tabular}

Caprino
a) Moxotó ( )
b) Canindé ( )
c) Anglo Nubiano ( )
d) SRD (Sem Raça Definida) ( )

8.3. Raças utilizadas

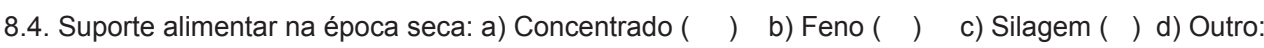

Ovino

a) Morada Nova ( )

b) Santa Inês ( )

c) SRD (Sem Raça Definida) ( ) e) Não tem ( )

8.5. Utilização de esterco caprino nos roçados ou capineiras: $\operatorname{Sim}(\quad)$ Não ( ) Uso de capineira:

8.6. Pressão de pastejo ( $N^{\circ}$ de animais/ha): 


\section{ARMAZENAMENTO DA ALIMENTAÇÃO ANIMAL}

Sim ( ) Não ( ) a) Estoque para um ano ( ) b) Estoque para mais de um ano ( )

10. REDUÇÃO DOS REBANHOS NA ÉPOCA SECA

$\operatorname{Sim}(\quad)$ Não ( ) a) Antes das estiagens ( ) b) Durante as estiagens ( )

11. ESPÉCIES VEGETAIS DE MAIOR UTILIZAÇÃO ANIMAL

a) Palmatória ( ) b) Faxeiro ( ) c) Mandacaru ( ) d) Faveleira ( ) e) Xique-xique ( ) f) Marmeleiro ( ) g) Maniçoba (

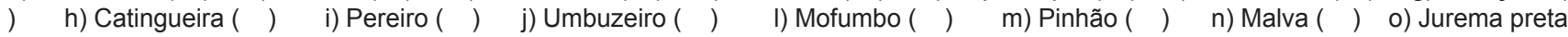
$\begin{array}{llll}( & \text { p) Jurema branca ( ) } & \text { q) Coroa de frade ( ) r) Outro: }\end{array}$

12. PARTE DAS PLANTAS CONSUMIDAS PELOS CAPRINOS
a) Plântula ( )
b) Folha nova ( )
c) Folha madura (
d) Caule e folhas ( )
e) Flor ( ) f) Ramos ( ) g) Fruto ( )

\section{ORGANISMOS EDÁFICOS MAIS ENCONTRADOS}
a) Ácaro ( ) $\quad$ b) Aranha ( )
c) Besouro ( )
d) Escorpião ( )
e) Formiga ( )
f) Cupim ( ） g) Lagarta/emboá i) Outro: h) Grilo/gafanhoto ( )

$($ )

14. LOCALIZAÇÃO DOS ORGANISMOS EDÁFICOS
a) Pastagem nativa ( )
b) Mata nativa ( )
c) Área de reserva ambiental ( )
d) Plantio ( )
e) Outro:

15. OS ORGANISMOS EDÁFICOS SÃO BENÉFICOS AO SOLO: Sim ( ) Não（） 16. ORIENTAÇÃO TÉCNICA PARA ENFRENTAR AS ESTIAGENS

16.1. Informados das previsões de chuvas $\operatorname{Sim}(\quad$ ) Não ( ) 16.2. Fazem experiência Sim ( ) Não （） Quais:

17. Outras informações: 



\section{RA’E GA: O ESPAÇO GEOGRÁFICO EM ANÁLISE}

ISSN $2177-2738$

\section{DIRETRIZES PARA O AUTOR}

A revista $R A^{\prime} E$ GA - O Espaço Geográfico em Análise é um veículo de publicação do Departamento de Geografia e Programa de Pós-graduação em Geografia da Universidade Federal do Paraná, sendo que ela recebe contribuições científicas na forma de texto relacionadas à ciência geográfica e áreas afins. Os artigos são submetidos à apreciação do Conselho Editorial da Revista, que acata ou não a publicação. Essa decisão será comunicada aos autores via e-mail, sem compromisso de devolução dos originais.

\section{I - Orientação geral}

1. O original deverá ser submetido ao sistema eletrônico de revistas: SER (www.ser.ufpr.br/raega), além de uma cópia em CD-R a ser enviada para o Editor Científico para fins de arquivo (depois de submetida ao sistema SER).

2. Os artigos devem ter de 10 a 30 páginas digitadas, incluindo figuras, tabelas e referências. Em casos especiais, a serem avaliados pelos editores, serão aceitos originais com número superior de páginas.

3. Os artigos serão preferencialmente escritos em português ou espanhol.

\section{II - Formato do texto}

1. Os textos dos trabalhos devem ser digitados em computadores tipo IBM-PC utilizando-se o programa MICROSOFT WORD FOR WINDOWS. Os textos devem ser digitados em letra Arial, corpo 12, com indicação de parágrafo, espaçamento 1,5, respeitando as normas da ABNT .

2. As figuras devem ser enviadas em formato digital BMP,.TIFF (não comprimido) ou .JPG e, no caso de tabelas e gráficos, devem ser feitos com o MICROSOFT WORD FOR WINDOWS ou MICROSOFT EXCEL, devidamente acompanhados de cópia em papel, e respeitando as medidas máximas de $21 \mathrm{x}$ $27,5 \mathrm{~cm}$. O texto deve indicar o local das figuras e tabelas.

3. As figuras serão publicadas preferencialmente em preto e branco. Se houver necessidade das figuras serem publicadas coloridas, o custo ficará a cargo do autor. Nesse caso deve ser consultado o editor.

4. Figuras e tabelas devem apresentar título e legendas em português ou espanhol.

\section{III - Organização dos textos}

Na primeira folha deverá constar o título (português e inglês), nome(s) do(s) autor(es), vínculo institucional e titulação. Na segunda página deverá constar o resumo (inglês e português) em um único parágrafo que contenha entre 5 e 10 linhas e palavras-chave (no máximo cinco palavras).

\section{IV - Referências e citações}

De acordo com a NBR-10520:2001 da ABNT, as referências deverão ter chamadas no texto pelo(s) sobrenome(s) do(s) autor(es), em maiúsculas, com data e paginação, quando dentro de parêntesis: (SANTOS, 1995, p.90) e apenas com a primeira letra em caixa alta, com as outras em caixa baixa, quando inseridas na frase: Segundo Santos (1995, p.8). Caso um mesmo autor citado tiver mais de uma publicação no mesmo ano, identificar cada uma delas por letras, (SANTOS, 1995a, p.6). Somente as referências citadas no texto deverão constar ao final do texto, em ordem alfabética, e elaborada de acordo com a NBR-6023:2000 da ABNT. 


\section{Livros}

SOBRENOME, Nomes. Título do livro. Local de Edição: Editora, data.

\section{Partes de livros}

SOBRENOME, Nomes (do autor do capítulo). Título do capítulo. In: SOBRENOME, Nomes (Ed., Org., Comp.) Título do livro. Local de Edição: Editora, ano. Número do Capítulo, p. página inicial - página final do capítulo.

\section{Artigos de periódicos}

SOBRENOME, Nomes. Título do artigo. Título do Periódico, Local de publicação, número do volume, número do fascículo, p. página inicial - página final, ano.

\section{Trabalhos acadêmicos}

SOBRENOME, Nomes. Título do trabalho acadêmico. f. Tese/Dissertação/Monografia (Doutorado/Mestrado/ em ...) - Setor, Universidade, local da defesa, data de defesa.

\section{Trabalhos em eventos}

SOBRENOME, Nomes. Título do trabalho. In: NOME DO EVENTO EM CAIXA ALTA, número do evento, ano de realização, local. Título...(Anais, Atas, Proceedings e etc.). Local de publicação: Editora, data, página inicial-final.

\section{Artigos de periódicos online}

SOBRENOME, Nomes. Título do trabalho. Fonte. Disponível em: <endereço eletrônico>. Acesso em: data (dia/mês/ano).

As citações textuais de até três linhas deverão aparecer no decorrer do texto, na mesma letra e entre aspas. As citações de mais de três linhas deverão ser digitadas com recuo, sem aspas nem itálicos e em letra de tamanho menor do que aquela do texto principal. Em ambas as citações deve ser referido o SOBRENOME do autor, ano, página.

RA'E GA: O Espaço Geográfico em Análise

Av. Cel. Francisco H. dos Santos, 100 - Jardim das Américas - Centro Politécnico

CEP 81532980 - Caixa Postal 19001 - Curitiba - PR

Fone: (41) 3361-3454 - Fax (41) 3361-3244

e-mail: raega@ufpr.br - web site: www.geografia.ufpr.br/raega 


\section{RA’E GA: O ESPAÇO GEOGRÁFICO EM ANÁLISE}

ISSN $2177-2738$

\section{INSTRUCTIONS TO AUTHORS}

The RA'E GA - O Espaço Geográfico em Análise journal, published by the Department of Geography and the Post-Graduate Studies Program in Geography - Master's and Doctorate's Level of the Federal University of Paraná, receives scientific contributions related to the geographic science and related areas. Articles may be published once approved by the Editorial board. Authors who submitted papers will receive the Editorial board's decisions by e-mail. Originals of submitted papers may not be returned to authors.

\section{I - General rules}

1. Originals should be sent to SER (Electronic Journal System) at the following address: <www.ser.ufpr.br/ raega>. After that, a CD-R copy must be sent to the Editor to be part of our filing system.

2. Papers should not be longer than 30 pages and not shorter than 10 pages, including fi gures, tables and references. In some special cases, which will be analyzed by the Editor, longer originals may be submitted.

3. Papers should be written either in Portuguese or in Spanish.

\section{II - Text format}

1. Papers should be typed in IBM-PC computers; MICROSOFT WORD FOR WINDOWS program should be used. They also should be typed in Arial letters, size 12, 1.5 spaced lines indenting first lines of paragraphs; ABNT rules should be followed.

2. Figures should be sent in BMP, .TIFF (not compressed) or .JPG digital format. Tables and graphics should be done by means of MICROSOFT WORD FOR WINDOWS or MICROSOFT EXCEL. Figures, tables and graphics should be sent printed, and they should not exceed $21 \times 27,5 \mathrm{~cm}$. Texts should indicate the appropriate place for figures and tables.

3. Figures should be published in black and white. Authors should agree to pay for additional costs in case of colored figures; these cases will be analyzed by the Editor.

4. Figures and tables should have titles and subtitles either in Portuguese or Spanish.

\section{III- Text organization}

The first page should contain: the title (both in Portuguese and in English), the author's names, Institution and titles. The second page should include an abstract (both in Portuguese and in English), in an only paragraph with 5 to 10 lines, and at most 5 (fi ve) key words.

\section{IV - References and citations}

According to NBR-10520:2001 from ABNT, the references should be called in the text by the author's surname in capital letters, date and page when in parenthesis (SANTOS, 1995, P. 90) and in small letters when within a sentence: According to Santos $(1995$, p. 8). If the same cited author has more than one publication in the same year, each one should be identified with letters, (SANTOS, 1995a, p. 6). Only the references that have been cited in the text should be mentioned in the reference list, in alphabetical order and created according to the NBR-6023:2000 from ABNT. 


\section{Books}

SURNAME, Names. Title. Place: Publisher name, date.

\section{Parts of books}

SURNAME, Names (chapter author). Chapter title. In: SURNAME, Names (Eds.; Org.). Book title. Place: Publisher name, year. Chapter number, chapter page number range (p. 10-18).

\section{Periodical articles}

SURNAME, Names. Article title. Journal Title. Place, volume number, issue number, p. page number range, year.

\section{Academic reports}

SURNAME, Names. Report title. Total page number. Thesis/Dissertation/Monograph (Doctory/ Mastery in ...) - School of ..., University, Place, date.

\section{Papers presented at meetings}

SURNAME, Names. Paper title. In: CONFERENCE NAME IN CAPITAL LETTERS, conference number, year, Place. Title... (Annals, Acts, Proceedings). Place: Publisher name, date, page number range.

\section{Online journal articles}

SURNAME, Names. Article title. Publisher. Journal Title. Place, volume number, issue number, p. page number range, year/date. Available at: <http://address>. Captured in: day/month/year.

Quotations of three lines or shorter should be showed in "quotation marks" and in the same font-size in the running text. Quotations of more than three lines should be indented at the left margin throughout, without any quotation marks or italics and in a smaller font than the main text. Both must be referred to as AUTHOR'S SURNAME, year, pages.

RA'E GA: O Espaço Geográfico em Análise

Av. Cel. Francisco H. dos Santos, 100 - Jardim das Américas - Centro Politécnico

Zip Code: 81532980 - P.O. Box: 19001 - Curitiba - PR

Phone number: (41) 3361-3454 - Fax number: (41) 3361-3244

e-mail: raega@ufpr.br - web site: www.geografia.ufpr.br/raega 


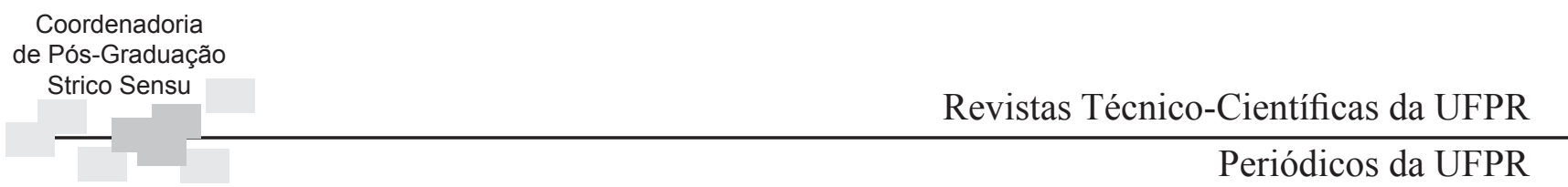

A Universidade Federal do Paraná instituiu o Sistema Eletrônico de Revistas (SER), abrindo um importante canal de interação entre usuários e a comunidade científica. Neste espaço estão listadas as Revistas Técnico-Científicas publicadas com recursos próprios ou com recursos do programa de apoio à publicação instituído pela UFPR.

O SER utiliza-se do Open Journal System, software livre e com protocolo internacional que permite a submissão de artigos e o acesso às revistas de qualquer parte do mundo. Nesse sistema já estão cadastradas 42 revistas da UFPR, abrangendo diversas áreas de conhecimento.

O sistema pode ser acessado por AUTORES, para a submissão de trabalhos, CONSULTORES, para a avaliação dos trabalhos, EDITORES, para o gerenciamento do processo editorial e USUÁRIOS, interessados em acessar e obter CÓPIAS de artigos já publicados nas revistas.

A SUBMISSÃO de artigos é feita por meio eletrônico e o autor poderá fazer o ACOMPANHAMENTO do processo de AVALIAÇÃO por parte dos consultores até a editoração final do artigo. As NORMAS de publicação e demais instruções, bem como os endereços dos editores são encontrados nas páginas de cada revista.

O trabalho de editoração de algumas revistas (Boletim Paranaense de Geociências, Desenvolvimento e Meio Ambiente, Educar em Revista, Extensão em Foco, História: Questões \& Debates, RA'E GA: O Espaço Geográfico em Análise, Revista de Economia e Revista Letras) é supervisionado pela EDITORA UFPR, que conta com corpo editorial especializado que se ocupa da revisão final dos volumes de seus respectivos periódicos, dentro dos padrões estabelecidos pela Editora. Findo o processo de editoração, uma cópia (pdf) dos artigos é disponibilizada em meio digital, dentro do Sistema SER, enquanto outra segue para impressão nas gráficas determinadas para cada publicação.

Para submeter um trabalho pela primeira vez será, antes, necessário entrar em CADASTRO. Uma vez cadastrado, abre-se uma caixa de diálogo indicando os passos a serem seguidos para o processo de submissão do artigo. Desejando apenas consultar trabalhos já publicados, basta acessar ARQUIVOS e obter o artigo desejado.

O SER oferece ainda o Public Knowledge Project, poderosa ferramenta de pesquisa, com acessibilidade global. Para fazer a busca por um tema de seu interesse utilizando essa ferramenta basta clicar em PKP e, em seguida, digitar uma palavra-chave na caixa de diálogo. Com isso você acessará artigos sobre o tema de seu interesse publicados em diversas partes do mundo.

Universidade Federal do Paraná

Pró-Reitoria de Pesquisa e Pós-Graduação (PRPPG)

R. Dr. Faivre, 405 - Ed. D. Pedro II, $1^{\circ}$ andar, Curitiba, Paraná, Brasil

CEP: 80060-140 - Telefone: (41) 3360-5227/ 3360-5335 - FAX: (41) 3360-5113

ser@ufpr.br

prppg@ufpr.br 